International

Medical Society

http://imedicalsociety.org

\title{
Group in Nursing: a Concept Analysis
}

Glícia Mesquita Martiniano Mendonça', Maria Vilani Cavalcante Guedes², Maria Célia de Freitas ${ }^{2}$, Lúcia de Fátima da Silva ${ }^{2}$, Maria Adelane Monteiro da Silva ${ }^{3}$, Francisca Alanny Rocha Aguiar ${ }^{4}$, Leidy Dayane Paiva de Abreu5 ${ }^{5}$ Juliana Vieira Figueiredo ${ }^{5}$, Diane Sousa Sales ${ }^{5}$, Ana Vírginia de Melo Fialho ${ }^{2}$

\section{Abstract}

Objective: To analyze the concept of group in nursing publications based on the evolutionary method.

Method: Evolutionary conceptual analysis using the method proposed by Rodgers. We sought to identify the concept; search for articles on health databases; identify attributes, antecedents and consequences of the studied phenomenon.

Results: The essential attributes of the group were: Participatory; Therapeutic; Structured; and Educative. The background identified: Group Setting and Need for Health. Consequences extracted from the studies were: Autonomy; Behavior change; Empowerment; Learning; and Integration.

Conclusion: It is understood that the concept of group has the purpose of encouraging and facilitating the practice of this technology by professionals.

\section{Keywords}

Nursing; Group strategy; Health education; Group practice; Group structure; Health promotion.
1 Nurse. Master's student in the Graduate Program in Clinical Care in Nursing and Health at the State University of Ceará, UECE.

2 Nurses. Teachers in the Graduate Program in Clinical Care in Nursing and Health of the State University of Ceará. UECE.

3 Nurse. Coordinator of the Nursing course at Vale do Acaraú State University, UVA.

4 Nurse. Doctorate in Collective Health from the University of Fortaleza, Unifor.

5 Nurses. PhD students in the Graduate Program in Clinical Care in Nursing and Health of the State University of Ceará, UECE.

\section{Contact information:}

\section{Glícia Mesquita Martiniano} Mendonça.

Address: Rua Raimunda Rosa de Andrade, 104. Santa Quitéria, Ceará, Brasil.

Tel: (88) 99305-9770

Đ glicia_martiniano@hotmail.com

\section{Introduction}

Concepts are elaborated throughout history and bring significant contributions to the production of knowledge. Considered symbols of what happens in the world of real phenomena and tools for researchers and professionals, such concepts need to be clarified and 
defined in the prospect of a more consistent and intelligible use, in order to contribute to improving the quality nursing care [1].

The concept is considered an abstraction that reflects the phenomena. These are dynamic, as they emerge and are transformed through new studies, experiences and reflections on meanings and interpretations, and are depend on the context instead of being universal and inflexible [2].

Many of the concepts in nursing are adaptations of the constructs of other disciplines, through a process of transposition and re-definition. The specificities of the characteristics of a concept define its dynamics, while defines also the use and relationship with other concepts for clarity in practice, teaching or research [3].

Nursing productions have been observed to increase along with the development of technology, whether hard, soft-hard or soft; however, the number of works mentioning or using soft technologies or inter-relationships is scarce. This may be caused by the difficulty that professionals have in defining what such technologiesare and in recognizing them as technological resources [2].

The group space is where the meeting of different ways of being takes place, with production of subjectivity [4]. This premise gains sense as we understand the group as a space for free expression that may favor the necessary mechanisms to change behaviors, to foster mutual support and learning, as these are some therapeutic factors that classify the group as a soft technology. Thus, the use of groups is effective as a health education tool.

Different types of groups are current or potentiaIly available for participants. It is possible, and sometimes advantageous, to look at each separate group as distinct entities trying to determine whether or not they will satisfy the specific needs of a specific participant. There is also an advantage in trying to categorize available and potential groups. Categories help to focus the thinking of the reader in similar and distinct aspects of various groups; and help the professional and the participant to bring some order to the apparent public and professional peculiarities existing when considering which method or which group actually meets the needs of the participants [5].

Given the above, the importance of analyzing the concept of group in nursing stands out, emphasizing conceptual elements that permeate its settings and application in the practice of this science in order to provide broad understanding of the concept and contribute to its proper use. The objective of this study was to analyze the concept of group in nursing publications based on the evolutionary method.

\section{Methods}

The analysis of concept of the material was carried out using the Evolutionary Method [2]. In this method, the analysis of the evolution of a concept happens in an inductive and rigorous way. It identifies its importance, relevance and meaning, and it is seen as a dynamic, broad, absolute and clear [2]. The method has applicability for this study, and six steps are proposed: 1) Identifying the concept; 2) Selecting a suitable area for the collection; 3) Collecting data to identify the attributes and the conceptual basis; 4) analyzing the data related to the characteristics of the concept; 5) Identifying, if necessary, an example of concept; and 6) Determining the implications and assumptions for the concept.

The identification of concept came from a concern of the researchers on the use of the term in professional practice without a clear definition. After this identification, a search for articles was performed. To locate literature, the following equation of search was used: ("groupstructure" AND "healtheducation" AND "nursing"). The bibliographic survey was carried out through consultations in the databases Latin American and Caribbean Health Sciences (LILACS), Spanish Bibliographic Index of Health Scien- 
ces (IBECS) Cumulative Index to Nursing \& Allied Health Lietrature (CINAHL), in the library Scientific Eletronic Library Online(SCIELO) and portal National Library of Medicine (PubMed).

Inclusion criteria defined for pre-selection of studies were: present the definition of group in the context of nursing, answer the main question; be electronically available in full-length, in any language; and produced by nurses, with collaboration or not with other health professionals. Editorials, letters to the editor, works published in event annals, dissertations and theses and repeated articles were excluded.

It is noteworthy that the search in the databases happened concomitantly, but individually, by two of the authors of this research. This strategy was adopted in order to validate the search. Furthermore, each database was accessed in a single day, with data collection conducted in April 2016.

Initially, the process of selection of studies was carried out by thoroughly reading the titles and abstracts, so that studies that met the above inclusion criteria were taken for final selection. For final selection, a critical analysis was held and key information were extracted from each article selected, according to an instrument developed by the authors, with identification of study (source, title, location, author, year and objectives); methodological design (method and approach); and critical analysis (results and conclusion).

In the third step, we sought to highlight the information that correspond to the elements referred to the attributes and contextual basis of group, guided by the definitions and questions of the evolutionary method of Rodgers (Table 1).

Data analysis (fourth stage of concept analysis model) focused on identifying the consensus on the use and meaning of the descriptive elements of group as a means to establish the current state of knowledge about the concept. For analysis of concept, data were reviewed and organized in an inductive and thematic way. A model case was pro- duced, referring to the fifth step of the method, in order to translate an observation of the "real life" to demonstrate an exemplary case of the concept.

In order to identify hypotheses and implications for the development of concept (sixth step of the method), we attempted to do a process that identifies a consensus or state of the art of knowledge, and thus provides an important basis, considered essential for future research [2].

The review was composed of eight articles, the presentation of results was organized in tables and figures with the aim to clarify and reveal the current state of knowledge related to the concept of interest.

\section{Results and Discussion}

The method of evolutionary concept analysis is characterized by taking into consideration the aspects and contextual dependence as factors influencing the concept. The eight articles that made up our universe of study about attributes and conceptual base, formed by antecedents and consequences, were inductively and descriptively analyzed.

The analysis of the publications in the sample allowed the identification of attributes, antecedents and consequences, expressed in Figure 1 and Table 1.

Table 1. Definitions and questions of the evolutionary method of Rodger.

\begin{tabular}{l|l} 
Analyzed item & \multicolumn{1}{c}{ Questioning } \\
Attributes & $\begin{array}{l}\text { What is the group definition in nursing? } \\
\text { What features are indicated for the } \\
\text { concept of group in nursing? }\end{array}$ \\
Antecedents & $\begin{array}{l}\text { What events, situations and/or } \\
\text { phenomena contribute to the imminence } \\
\text { and existence of the concept of group in } \\
\text { nursing? }\end{array}$ \\
\hline Consequences & $\begin{array}{l}\text { What are the events or situations } \\
\text { resulting from the group in nursing? }\end{array}$
\end{tabular}

Source: adapted from Rodgers (2000) 
Figure 1: Conceptual framework of Group in Nursing. Fortaleza, Ceará, Brazil, in 2016 Source: own elaboration. 2016.

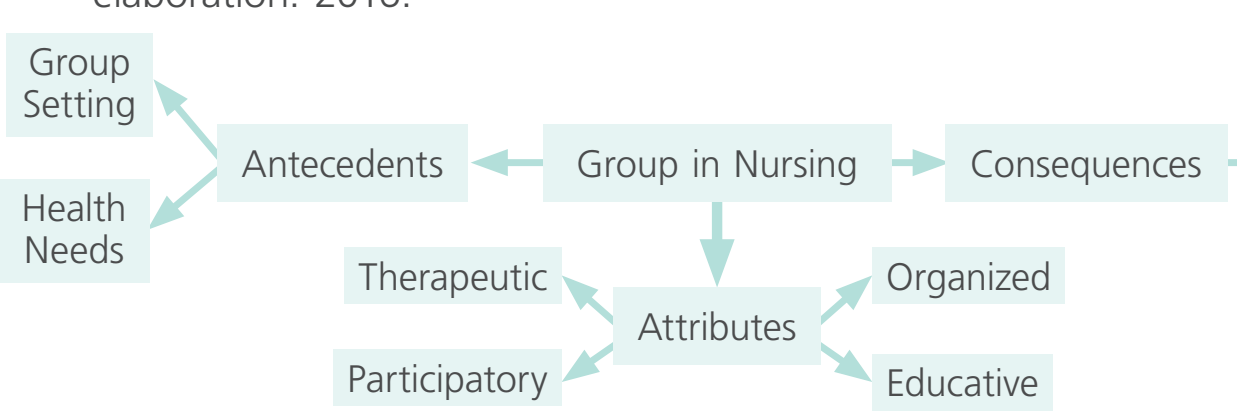

Autonomy

Change of Brehaviour

Empowerment

Learning

Integration

\section{Unveiling the attributes}

Attributes are conceptualized as the real definition and expressions or words frequently used by authors to define the phenomena1. The attributes of the concept emerged from the definitions used by the authors to define group in nursing were presented clearly and didactically in Figure 1, and they were "therapeutic", "participatory", "organized" and "educative".

Group is understood as a key element in the pursuit and promotion of a space where teaching and learning takes place, where there is dialogue and exchange of knowledge.

Fernandes [8] presents the group as a space of experimentation of awareness, feeling and selfmotivated action, in the sense that it can be a space for creative adjustment and personal growth of the participant. It is noticed that the attributes linked to this definition trigger the interest in using a more targeted form of group, away from the abstract space, to gain the form of a nursing intervention.

The group is designed not only as a space that nursing can use for providing care, but also and mainly because it is an intervention therapy, a need that involves peculiar circumstances, as there is no way to provide care for the health of an individual with integrality if their emotional/physical/social component is affected.

The group is participatory and, at the same time, stimulates the independence of its members, allowing an active and creative adaptation to reality, and more mature and free choices9. The group consists in a soft technology [10] of health education that gives its participants rich moments in the search of empowerment and self-care, and achieve goals set previously by all together.

The role of the coordinator in driving the group is another important factor that represents an additional attribute, the administration of time promotes a significant learning space [11]. The group is educative when allows change of behavior based on the health needs of its participants, promoting health and exchange of experience.

Thus, the group process happens through the meaning of situations experienced by individuals in the group and by the group, forming a continuous phenomenon, mobiliser of changes and concerns with the reality [12].

The coordination of group activities is a task that requires knowledge, specific skills and attitudes from the health professional that, in general, are not developed during their training during the attainment of their degree [11].

Another definition is that the group is a structured set of people, organized from psychological interactions among its members and by the awareness that they must belong to this set [13].

Thus, it is essential that health professionals prepared themselves to work with group interventions. It is necessary to have a theoretical basis to provide them with subsidies to make this work more pro- 
ductive and healthy and the human relations more satisfactory. Moreover, it is important to have the resources to enable them to assess whether, in fact, care

group can achieve the goals and positively contribute to the lives of the participants [14].

\section{Elucidating the background}

The antecedents correspond to situations, events or phenomena that preceded the concept of interest. From the identification of this element, it is possible to understand the interference of context in the definition of group [1].

The articles examined revealed antecedents that emerged more frequently and contributed to the imminence of the concept and were presented in

\section{Figure 1.}

Among the antecedents, it was observed that the "Group Setting" and the "Need for health" are singled out as a problem cores triggering the formation of groups in nursing.

It is essential that the coordinator reflect on the strategy to be used with the group, the planning, the way a group begins and ends, in order to respect the fundamentals of group dynamics, not interrupting phases of the group or manipulating emotions and actions of the members [8]. The group setting that is configured for nursing intervention allows to develop the potential of individuals and of the group itself, allowing it to become increasingly sensitive and complex in the interaction and group communication, indicating that this positively contributes in the lives of its members and to the therapeutic change of people.

Group activities developed by nursing are, in most health services, supported by a prescriptive model, focusing on achieving desired behaviors for the control and prevention of diseases [15]. Thus, its approach is conceived in the logic of individual intervention applied to group reality, what does not always guarantee the adhesion of the subjects and the effectiveness of the group.
Group interventions not are intended to replace individual care from professionals in the institutions, but must be complimentary to therapeutic projects geared at the health needs of the public [13]. Based on the health needs of each participant, it becomes possible to achieve the goals and

the experiences shared in the group offer support to overcome problems inherent in life situations.

It is noteworthy that these antecedents have perceptions of the authors as to what fidgeted them and triggered the formation of the group and that, through this awareness, it is possible to promote health in an environment where everyone learns and receives support.

The importance of identifying the antecedents covers a group model approach which facilitates understanding customers in their context, meeting their real needs, based on a dialogical relationship that enables the sharing of knowledge and experiences, and the development of more effective coping strategies, thus contributing to the promotion of health of the participants.

\section{Exploring the consequent}

The consequences of the phenomenon studied are the consequences of the concept, which are defined as those resulting from the implementation of the phenomenon investigated [1].

It is clear in the articles analyzed that when special attention is given to the movement of the group by a qualified hearing of the needs expressed or latent of participants, "autonomy", "change of behavior", "empowerment", "learning" and "integration" can be reached as consequential.

The group intervention can contribute to promotion, improvement and effectiveness of health treatments and can be used as a strategy to enhance the autonomy of participants and enhance empowerment for decision-making and behavior change necessary for their wellbeing and recovery.

Gaps in the practice of group activities by nurses were identified regarding the use of the theoreti- 
cal framework that may sustain the group development. These practices, when carried out without adequate and consistent support, cause the trivialization of the intervention [16]. It is necessary that nursing rethink their practice and seek to develop specific knowledge

to the management and coordination of group interventions focused on the search for therapeutic factors and strengthening the profession as a science.

When driving the group in that direction, significant learning space, support for exchange of experiences and integration of participants is promoted. All of this favors and allows the group to gain form as a nursing intervention [17].

Thus, the practice of groups allows therapeutic factors to their patients with great effectiveness, providing rich experiences through collectivity. Using a theoretical-methodological framework in performing groups is something that provides a better basis with targeted objectives to be achieved.

Finally, we point out that the use of the group as a resource to assist people is as old as the human development itself in the care of the other [8]. However, it is essential to use this intervention in the search of care directed to psychological, philosophical, anthropological and social dimensions that permeate the object of the care, valuing holistic care in the search for therapeutic factors that allow the well-being of the participants.

\section{Clarifying Substitute Terms}

By substituting terms, one understands the use of different words or expressions throughout the body of the text [2].

Some of the words and expressions used to replace the concept "group in Nursing" are: "group technology" [9], "group activities" [10], "group interventions" [13], "visiting groups" [16], "group" [11], "self-care" [12] and "focus group" [14, 15].

The inductive analysis of the eight scientific productions demonstrated the use of the various subs- tituting terms, which were related to the work context, the group definition, the methodology used, among others. These aspects can produce barriers, since there is no real standardization of the concept and, consequently, repercussions on the lack of knowledge of the use of groups, besides generating practices without theoretical and methodological foundation and banalizations of the term.

When reflecting on the researches, especially the bibliographical ones, this diversity of substitute terms is responsible for biases in the methodological route and obstacles for the scientific deepening. Sometimes a data collection technique is identified and used as a group concept as health promotion technology.

After identification of attributes, contextual bases and terms substitutes of group in nursing, the model case was created for the concept analyzed.

\section{Model case}

Luiza has been a nurse in Primary health care for two months, obtained her degree recently, and during nursing consultations for hypertensive patients, she had her interest awakened for organizing a group with these patients after providing care for their health needs. During the undergraduate course, she was effectively prepared to play the role of coordinating groups, and is cognizant of the theoretical and methodological frameworks available, the attributes of a group coordinator and the therapeutic factors produced. In the meeting of the team, she raised the interest of others and made everyone aware of the therapeutic benefits of the group involving the whole team. Community health workers started to invite their hypertensive patients right after that, and telling the good news, the receptionist informed users, who, in turn, would inquire the unit about the day and time of the meeting, the watchman reinforced the invitation at the exit with a beautiful smile, the doctor would give instructions on the importance of participating. Meanwhile, Luiza informed the coordination of her 
proposal and she was very much encouraged, then she prepared a research project to submit to the Ethics Committee of the Health Department, and received the assent. After that, she found a space in the basic health unit that would be more suitable, giving priority to the comfort of the group, as well as lighting and cleaning and cared for participants were warmly greeted as she planned activities. In the day and scheduled, participants were there, present, and Luiza drove the moment with joy, held a dynamic integration where all introduced themselves and knew each other in a fun way,. They evaluated the moment as crucial, highlighting that all had lived there similar situations and that they felt comfortable. Then, a health agreement was carried out. All agreed on the group's rules of coexistence, the issues they wanted to discuss, duration, frequency, period and type of group that would be, and at the end of that moment, participants evaluated the activity developed showing satisfaction of having participated in a group according to their wishes. To close, the nurse facilitated the discussion of the importance of knowledge on hypertension for developing elf-care and health promotion. Some participants expressed their anxieties, fears and doubts, while Luiza watched and actively listened to them, taking into account the therapeutic factors involved in that moment. The next meeting was scheduled as agreed in the health contract and participants were looking forward to the next moment of meeting, even inviting people they know to participate as well.

The findings helped in the analysis of the definitions of the concept studied, as well as made it possible to prepare the definition of group in nursing as follows: therapeutic intervention which is organized, participatory and educational, and related to the health need and group framework for promoting learning, empowerment, autonomy, change of behavior and integration between participants.

\section{Conclusions}

The conceptual analysis, from the perspective of the evolutionary view of Rodgers, allowed to understand that the diversity of terms used have contextual and temporal influences. It is believed that this diversity is a reflection of the practice by professionals, requiring theoretical and methodological deepening.

The need for nursing build a group intervention model that facilitates understanding customers in their context, meeting their real needs, based on a dialogical relationship that enables the sharing of knowledge and experiences among the members and the development of strategies of more effective coping, thus contributing to the promotion of health of the participants. This whole process should take place through participatory, critical, reflective and transformative action, based on theory and method.

As limitations of the present study, we point the restriction of the concept analysis of group in nursing in Brazil and in international databases, in articles made available on the world wide data, what may reflect an incomplete characterization of state of the art of the concept.

The need for investigations with the use of theoretical frameworks and conceptual analysis is stressed, besides the incentive for studies using descriptors that characterize and standardize the search amid the concept of group as technology that promotes health, in order to facilitate the search and knowledge by the academic community of articles of this nature.

\section{References}

1. Lopes MSV, Saraiva KRO, Fernandes AFC, Ximenes LB. Analysis of the concepto $f$ health promotion. TextoContextoEnferm (Florianópolis). 2010;19(3):461-8.

2. Rodgers BL. Conceptanalysis: an1. evolutionaryview. In: Rodgers BL, Knafl KA. Concept development in nursing: foundations, techniques, and applications. $2^{a}$ ed. USA: WB. Saunders; 2000.

3. Rodrigues, Amendoeira, pereira, 2013. 
4. Nogueira, A. L. G., Munari, D. B., Santos, L. F., Oliveira, L. M. D. A. C., \& Fortuna, C. M. (2013). Therapeutic factors in a group of health promotion for the elderly. Revista da Escola de Enfermagem da USP, 47(6), 1352-1358.

5. Loomis, M.E. Groups process for nurses. Saint Louis: MosbyCompany, 1979

6. Mendes KDS, Silveira RCCP, Galvão CM. Revisão integrativa: método de pesquisa para incorporação de evidências na saúde e enfermagem. TextoContextoEnferm. 2008; 17(4):758-64.

7. Howick J, Chalmers I, Glasziou P, Greenhalgh T, Heneghan C, Liberati A, et al. The Oxford Levels of Evidence 2. [Internet]. Oxford Centre for Evidence-Based Medicine The Oxford 2011 Levels of Evidence; 2011 [atualizadaem 2014; acessoem15 de abri 2016]. Disponível: http://www.cebm.net/ocebm-levels-ofevidence

8. Fernandes CNS, Bouttelet DM, Soares SM, Medeiros M. Habilidades e atributos do enfermeiro como coordenador de grupos. Rev RENE. 2008;9:146-53.

9. Oliveira NF, Munari DB, Bachion MM, Santos WS, Santos QR. Fatores terapêuticos em grupo de diabéticos. Rev Esc Enferm USP. 2009; 43(3):558-65.

10. Merhy EE. Em busca de ferramentas analisadoras das tecnologias em saúde: a informação e o dia a dia em um serviço, interrogando e gerindo trabalho em saúde. In: Merhy EE, Onoko $\mathrm{R}$, organizadores. Agir em Saúde: um desafio para o público. $2^{\mathrm{a}}$ ed. São Paulo: Hucitec; 2002. p. 113-50.

11. Munari DB, Lucchese $R$, Medeiros $M$. Reflexões sobre o uso de atividades grupais na atenção a portadores de doenças crônicas. CiencCuidSaude. 2009; 8:148-154.

12. Tavares DMS, Dias FA, Munari DB. Quality of life of the elderly and participation in group educational activities. Acta Paul Enferm. 2012;25(4):601-6

13. Crispim ZM, Munari DB, Salge AKM, Lucchese R. Atividades grupais na promoção da saúde feminina: revisão integrativa. RevRene. 2011; 12(3):633-44
14. Santos, L. F., Oliveira, L. M. D. A. C., Munari, D. B., Peixoto, M. K. A. V., \& Barbosa, M. (2012). Therapeutic factors in group support from the perspective of the coordinators and group members. Acta Paulista de Enfermagem, 25(1), 122-127. Crozeta K, Truppel TC, Meier MJ, Danski MTR. Determinantes e condicionantes para a implementação da consulta de enfermagem. CogitareEnferm. 2009;14(1):120-6.

15. Aase I, Hansen BS, Aase K. Norwegian nursing and medical students perception of interprofessional team work: a qualitative study. BMC Medical Education. 2014;14:170.

16. Chao MT, Abercrombie PD, Duncan LG. Centering as a model for group visits among women with chronic pelvic pain. JOGNN. 2012;41:703-10.

17. Batista JMF, Becker TAC, Zanetti ML, Teixeira CRS. O ensino em grupo do processo de aplicação de insulina. RevEletronica de Enfermagem. 2013;15(1):71-9.
Publish in International Archives of Medicine

International Archives of Medicine is an open access journal publishing articles encompassing all aspects of medical science and clinical practice. IAM is considered a megajournal with independent sections on all areas of medicine. IAM is a really international journal with authors and board members from all around the world. The journal is widely indexed and classified Q2 in category Medicine. 